\title{
Verrucous carcinoma: a retrospective diagnosis in three historic patients
}

\author{
Afshin Teymoortash • Carl E. Silver • \\ Alessandra Rinaldo $\cdot$ Antonio Cardesa • \\ Benedikt J. Folz • Alfio Ferlito
}

Received: 21 October 2013/Accepted: 28 October 2013/Published online: 9 November 2013

(c) Springer-Verlag Berlin Heidelberg 2013

Verrucous carcinoma is a highly differentiated variant of squamous cell carcinoma with slow-growing locally invasive malignancy but not metastatic potential. This tumor was first recognized in 1941 by Friedell and Rosenthal [1]; they reported on eight patients with oral cavity tumors. All had a habit of tobacco chewing. In each case, the origin of cancer in the buccal mucosa and on the alveolar ridge corresponded exactly to the area in which the quid was held. All the lesions developed slowly, were well differentiated and had a distinctive character. They were of a papillary verrucoid appearance, covered and surrounded by patchy areas of leukoplakia. Only moderate induration was present, and deep infiltration into the submucosal tissue was not evident. All patients were treated successfully by

The paper was written by members and invitees of the International Head and Neck Scientific Group (www.IHNSG.com).

\author{
A. Teymoortash \\ Department of Otolaryngology-Head and Neck Surgery, Philipp \\ University, Marburg, Germany \\ C. E. Silver \\ Departments of Surgery and Otolaryngology-Head and Neck \\ Surgery, Albert Einstein College of Medicine, Montefiore \\ Medical Center, Bronx, NY, USA \\ A. Rinaldo $\cdot$ A. Ferlito $(\square)$ \\ ENT Clinic, University of Udine, Piazzale S. Maria della \\ Misericordia, 33100 Udine, Italy \\ e-mail: a.ferlito@uniud.it

\section{A. Cardesa} \\ Department of Anatomic Pathology, Hospital Clinic, University \\ of Barcelona, Barcelona, Spain \\ B. J. Folz \\ ENT Department, Karl Hansen Clinic, Bad Lippspringe, \\ Germany
}

radiotherapy, and were followed up for maximal duration of 2 years. Only one of the eight cases developed regional metastases.

Seven years later Lauren V. Ackerman [2], who was aware of the publication of Friedell and Rosenthal, described his experience with the same variety of squamous cell carcinoma. He reported on 31 patients with oral and one patient with oropharyngeal squamous cell carcinoma with the typical clinical course, and characteristic histopathology, and coined the term "verrucous carcinoma". The epithelium was well differentiated and the basement membrane remained intact. However, he found that some tumors might be locally aggressive. He often observed cancer cells extending into the deeper soft tissue and invading bony structures. In only one patient a single metastatic lymph node was found. Verrucous carcinoma was not recognized in Europe until the 1976 report of Ferlito [3] classifying 2,052 malignant neoplasms of the larynx and hypopharynx treated at the University of Padua. The tumor is often referred to as "Ackerman's tumor" in his honor [4].

During the late nineteenth and early twentieth century, three celebrated cases of head and neck cancer occurred in highly prominent people; two heads of state, and the father of psychoanalysis. On reviewing the medical histories of these patients, we have concluded, based on available material, their lifestyles and the clinical courses of their diseases, that all three had verrucous carcinomas.

The case of the German Emperor Friedrich III (1831-1888) is extremely well known, is debated to this day, and almost caused an international incident. Even 125 years after his death, the discussion about his medical history and management still awakens interest. In the autumn of 1886 Friedrich, the Crown Prince of Germany, who was a pipe smoker, suffered from persistent 
hoarseness. A laryngoscopy by Prof. Ernst Gerhardt, in March 1887, revealed a $2 \times 4 \mathrm{~mm}$ nodule on the left vocal cord. Despite many sessions of galvanocautery this lesion recurred, and because of the suspicion of carcinoma, a tumor resection via laryngofissure was recommended. Morell MacKenzie, the renowned British laryngologist, was consulted. MacKenzie advised against the operation without biopsy proof of diagnosis. Three biopsies of the lesion were taken by MacKenzie and diagnosed by Rudolf Virchow, the founder of cellular pathology, as pachydermia verrucosa. Based on these findings, conservative treatment was followed. The clinical symptoms continuously worsened and in November 1887 the initial suspicion of a laryngeal malignancy was agreed on by all attending physicians. A laryngectomy was recommended. Friedrich decided against the radical surgery. A palliative tracheotomy was performed in January 1888. Two months later Friedrich succeeded Wilhelm I to the throne for 99 days until his death in June 1888. The autopsy after his death due to bronchopneumonia revealed an ulcerous squamous cell carcinoma of the larynx with an ipsilateral regional lymph node metastasis. A sputum specimen obtained from the tracheotomy 3 months before his death, examined by Waldeyer, had been considered "compatible with carcinoma" [5], and was the only microscopic evidence of cancer obtained while Friedrich was alive.

Since the histological specimens of Friedrich's larynx were lost during the second world war in Berlin, the definitive diagnosis of his disease is still speculative. However, based on the course of Friedrich's illness and the pathology reports about his laryngeal cancer, Pahor [6] suggested in a letter that his cancer should be considered as a verrucous carcinoma of the larynx, the first such case known in history. Several colleagues disagreed with this diagnosis because a cervical lymph node metastasis was present. But recently Cardesa et al. [7], based on current pathologic knowledge and clinical records, proposed that the tumor was a hybrid verrucous carcinoma. The hybrid type of verrucous carcinoma is a mixed tumor composed of both verrucous and conventional squamous cell carcinoma that is capable of metastasizing. The hybrid form is not uncommon. Some studies indicate that up to $10 \%$ of all laryngeal verrucous carcinomas are of the hybrid type [8]. Even Friedell and Rosenthal [1], and Ackerman [2] found regional metastases in their cases.

Ackerman's commentary about verrucous carcinoma offers an interesting explanation of the difficulties Virchow encountered in his inability to render a diagnosis of malignancy. "The biopsy material is often confusing. Superficial biopsies are often taken and a positive diagnosis of carcinoma cannot be made. Even with deep biopsies diagnosis may be difficult [2]". In addition, for detection of hybrid nests, usually located in the deeper portions of the cancer, serial sectioning of the whole specimen may be needed for demonstration of a conventional squamous cell carcinoma component.

While the larynx is the second most common location of verrucous carcinoma, the oral cavity is the most frequent site of this tumor in the head and neck [9]. In June of 1893 the White House physician found a $2-3 \mathrm{~cm}$ crater-like ulceration on the left palate of the president of the United States, Stephen Grover Cleveland (1837-1908). President Cleveland smoked cigars and used chewing tobacco. The biopsy from the lesion was reported as a low-grade epithelial malignancy. On July 1, a surgical team headed by Joseph Bryant, a prominent surgeon, performed a transoral partial maxillectomy on a specially equipped yacht, under the greatest secrecy. A second smaller surgery was performed on July 17 to remove residual lesions. After this procedure Cleveland lived free from recurrence for 15 years until his death by heart failure [10]. The primary histological diagnosis of a sarcoma could not be confirmed and the definitive diagnosis was squamous cell carcinoma. Finally, in 1980, a re-evaluation of the cancer specimens from Cleveland revealed the diagnosis of verrucous carcinoma [11].

Sigmund Freud (1856-1939), also a heavy cigar smoker, suffered from an oral lesion similar to Cleveland's. He visited his family physician, Felix Deutsch, and his friend Maxim Steiner in April 1923 because of a crater-like ulceration of his right posterior palate. They came to a clinical diagnosis of advanced oral cancer, but they did not tell him the truth; possibly because Freud was depressed by the death of his grandson. Nevertheless, Freud suspected the lesion was a cancer and contacted Markus Hajek, a laryngologist and rhinologist in Vienna. After partial removal of the histologically proven squamous cell carcinoma by Hajek, radiotherapy was administered followed by a superficial removal of the residual lesion without assessing safe margins. The operation was performed as an outpatient procedure [12]. After this initial hesitant treatment Freud suffered from severe pain and trismus. In September of the same year he contacted Hans Pichler, an oral surgeon, who carried out a second surgery in two stages. He performed a partial maxillectomy with removal of parts of the mandible as well as an excision of the submandibular gland and cervical lymph nodes. Histologic examination of the nodes failed to identify malignancy. However, only 1 month later residual oral disease was proven by biopsy. Until his death in 1939, a total of 34 procedures were performed without complete removal of the cancer. Freud's 16-year-long excruciating history of cancer with associated intractable pain, orocutaneous fistula, and unbearable smell eventually came to an end with an overdose of morphine [13].

The protracted course of his incompletely resected oral cancer with pN0 neck lets us hypothesize that his cancer 
was also a verrucous carcinoma. The better outcome of Cleveland's oral cancer compared to Freud's was undoubtedly due to the initial decision for complete resection which was performed under more suitable conditions by a surgical team using mirror-fortified electric light, a Luer cheek retractor, and electrocautery [14].

Verrucous cancer remains a diagnostic dilemma because of the difficulty of obtaining adequate biopsy material. Cleveland managed to keep his illness secret from the public, was cured by the surgery, and thus had a satisfactory outcome both politically and personally. Freud suffered severe loss of quality of life because of the persistence of his low-grade tumor. Friedrich's death from cancer affected the history of the world for the next century.

\section{References}

1. Friedell LH, Rosenthal LM (1941) The etiologic role of chewing tobacco in cancer of the mouth. JAMA 116:2130-2135

2. Ackerman LV (1948) Verrucous carcinoma of the oral cavity. Surgery 23:670-678

3. Ferlito A (1976) Histological classification of larynx and hypopharynx cancers and their clinical implications. Pathologic aspects of 2,052 malignant neoplasms diagnosed at the ORL
Department of Padua University from 1966 to 1976. Acta Otolaryngol Suppl 342:1-88

4. Ferlito A, Recher G (1980) Ackerman's tumor (verrucous carcinoma) of the larynx: a clinicopathologic study of 77 cases. Cancer 46:1617-1630

5. Folz BJ, Ferlito A, Weir N, Pratt LW, Rinaldo A, Werner JA (2007) A historical review of head and neck cancer in celebrities. J Laryngol Otol 121:511-520

6. Pahor AL (1993) Tracheostomy. J R Soc Med 86:308

7. Cardesa A, Zidar N, Alos L, Nadal A, Gale N, Klöppel G (2011) The Kaiser's cancer revisited: was Virchow totally wrong? Virchows Arch 458:649-657

8. Orvidas LJ, Olsen KD, Lewis JE, Suman VJ (1998) Verrucous carcinoma of the larynx: a review of 53 patients. Head Neck 20:197-203

9. Cardesa A, Zidar N (2005) Verrucous carcinoma. In: Barnes L, Eveson JW, Reichart PA, Sidransky D (eds) Pathology and genetics of head and neck tumours. WHO classification of tumours. IARC, Lyon, pp 122-123

10. Maloney W (2010) Surreptitious surgery on Long Island Sound: the oral cancer surgeries of President Grover Cleveland. NY State Dent J 76:42-45

11. Renehan A, Lowry JC (1995) The oral tumours of two American presidents: what if they were alive today? J R Soc Med 88:377-383

12. Adeyemo WL (2004) Sigmund Freud: smoking habit, oral cancer and euthanasia. Niger J Med 13:189-195

13. Lazaridis N (2003) Sigmund Freud's oral cancer. Br J Oral Maxillofac Surg 41:78-83

14. Weinberg MA, Wang B (2011) Head and neck cancer in two American presidents: case reports. Gen Dent 59:492-497 